\title{
The Behcet's Disease: An Uncommon Cause of Venous Thrombosis in the Tropical Area: 10 Cases
}

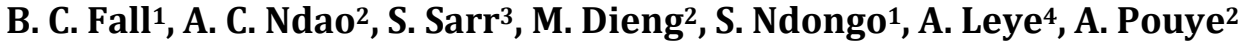 \\ ${ }^{1}$ Department of Internal Medicine, Dalal Jamm Hospital, Dakar, Senegal \\ ${ }^{2}$ Department of Internal Medicine, Le Dantec Hospital, Dakar, Senegal \\ ${ }^{3}$ Department of Cardiology, Le Dantec Hospital, Dakar, Senegal \\ ${ }^{4}$ Department of Internal Medicine, Pikine Hospital, Pikine, Senegal \\ Email: sndongo_medinterne@yahoo.fr
}

How to cite this paper: Fall, B.C., Ndao, A.C., Sarr, S., Dieng, M., Ndongo, S., Leye, A. and Pouye, A. (2017) The Behcet's Disease: An Uncommon Cause of Venous Thrombosis in the Tropical Area: 10 Cases. Open Journal of Internal Medicine, 7, 177-184.

https://doi.org/10.4236/ojim.2017.74020

Received: June 29, 2017

Accepted: December 25, 2017

Published: December 28, 2017

Copyright (c) 2017 by authors and Scientific Research Publishing Inc. This work is licensed under the Creative Commons Attribution International License (CC BY 4.0).

http://creativecommons.org/licenses/by/4.0/

\section{Abstract}

Introduction: The Behcet's disease is deemed to be scarce in Black Africa where data are still scattered. The purpose of our study is to describe the epidemiological, clinical, paraclinic and evolutive particularities of the patients whose presenting symptoms of the Behcet's diseases were a venous thrombosis. Patients and Methods: It was a descriptive, multicenter, and cross-sectional study lasting 15 months. We brought together all the cases of the Behcet's disease revealed by venous thrombosis. The diagnosis was based on clinical criteria of the international group of study of the Behcet's disease in 2007. Results: We have grouped 10 revealing thrombosis cases of the Behcet's diseases during our study period. The average age was 34 . The average wait period between the appearances of the early symptoms and the diagnosis of the very disease was 30 months. The admission motives were the abdominal pain ( 2 cases), a thrombophlebitis of the lower limb ( 2 cases), headaches ( 1 case), coma (1 case), a thrombophlebitis of the upper limb (3 cases). The thrombotic symptoms were exclusively venous-located. The seats of the thrombosis were the vena cava superior in $30 \%$ of the cases, the vena cava inferior in $20 \%$ of the cases, the veins of the lower limb in $20 \%$ of the cases, the cerebral vein in $20 \%$ of the cases, and the auxiliary vein in $10 \%$ of the cases. The treatment of the deep venous thrombosis consisted in all the cases of an effective anticoagulation associated with the colchicine. Primarily, the corticotherapy with a high dose was used in all the patients. One of them in the comatose stage, manifesting both cerebral thrombophlebitis and aseptic meningitis, had died. Conclusion: Behçet's disease is a disease of the young adult, but it must be evoked even in old age, with a view to appropriate man- 
agement, in order to avoid the complications of the disease. Although it is rare in our regions, it should be sought in the etiological assessment of venous thrombosis whatever the location.

\section{Keywords}

Behcet's Disease, Thrombosis, Senegal

\section{Introduction}

The Behcet's disease is a systemic vasculitis of various vessel sizes evolving by increase and remission. Even if it is ubiquitous, it is much more frequent in the mediterranean region. Vascular thrombosis, especially the venous ones are common in the course of this affection and can slow down the diagnosis. In fact, bipolar aphthosis, dermatological lesions and the ocular inflammation constitute the main symptoms of this disease [1].

It is deemed to be scarce in Black Africa where data are still scattered [2].

The purpose of our study is to describe the epidemiological, clinical, paraclinic and evolutive particularities of the patients whose presenting symptoms of the Behcet's diseases were a venous thrombosis.

\section{Patients and Methods}

It was a descriptive, multicenter, and cross-sectional study that was conducted from January $1^{\text {st }} 2015$ to April $1^{\text {st }} 2016$, lasting 15 months. We brought together all the cases of the Behcet's disease revealed by venous thrombosis. Those cases were hospitalized in the internal Medicine of CHN Pikine and CHU Dantec or referred by other services in particular Cardiology, Neurology, Cardiovascular Surgery or Infectious Disease.

We studied the epidemiological, clinical, paraclinic and evolutive particularities of the patients whose presenting symptoms of the Behcet's diseases were venous thrombosis.

The diagnosis was based on international criteria ICBD in 2006 [3]:

- Oral aphthosis: 1 point

- Genital aphthosis: 2 points

- Skin lesions: 1 point

- Vascular lesions : 1 point

- Ocular involvement: 2 points

- Positive pathergic test : 1 point

The diagnosis was established if the score was greater or equal to 3 points.

The collection tool was a survey form developed by a committee of experts and approved by an ethics committee.

\section{Results}

We have grouped 10 revealing thrombosis cases of the Behcet's diseases during 
our study period. The average age was 34, with a range of 22 and 69 years old. There was an apparent male predominance with 8 against 2 females. There were 2 smoking patients. None of them were alcoholic. We did not observe any family history of Behcet's disease. The average wait period between the appearances of the early symptoms and the diagnosis of the very disease was 30 months. The admission motives were shown on Figure 1. The initial hospital service was different (Figure 2). Mouth and genital ulcer were present in all of our patients (100\%) with an average of 3 flare-ups per year [3] [4] [5] [6] [7] (Figure 3).

The pathergy test was positive on 1 patient. Dermatological lesions, pseudofolliculitis type, were noticed in 3 patients. The thrombotic symptoms were exclusively venous-located. The thrombotic manifestation were exclusively of venous localization The thrombosis sites were the superior vena cava in 30\% of the cases (Figure 4 and Figure 5), the inferior vena cava in $20 \%$ of the cases, the veins of the lower limb in $20 \%$ of the cases, the cerebral vein in $20 \%$ of the cases, and the auxiliary vein in $10 \%$ of the cases (Table 1). There were 2 cases with neurological symptoms of the Behcet's disease of aseptic lymphocytic meningitis type and 1 case of anterior uveitis eye damage. There was neither articular nor digestive one. No pulmonary embolism was observed. The treatment of the deep venous thrombosis consisted in all the cases of an effective anticoagulation associated with the colchicine. Primarily, the corticotherapy with a high dose was used in all patients.

One of them admitted during the comatose stage, manifesting both cerebral thrombophlebitis and aseptic meningitis, had died.

\section{Discussion}

Behçet's disease (BD) is a systemic vasculitis of vessels of varying sizes evolving by thrust and remission.

There is no pathognomonic examination of $\mathrm{BD}$ and the diagnosis is based on clinical criteria such as those proposed by the International BD Study Group and, more recently, those of the International Team for the Revision of the International Criteria for BD [1] [3] [4]. It predominates in the Mediterranean basin, the Middle East and Japan [5]. In Africa data are still scattered [2].

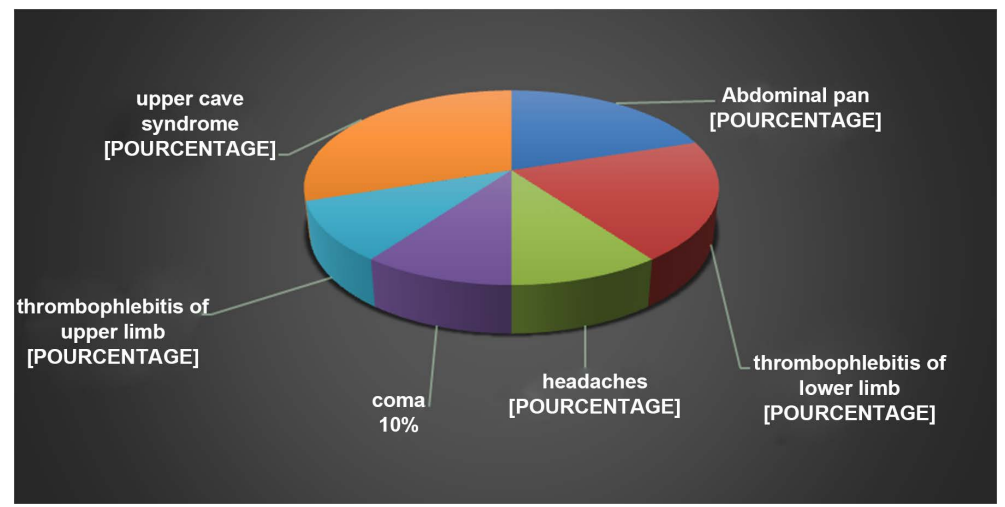

Figure 1. Admission motives. 


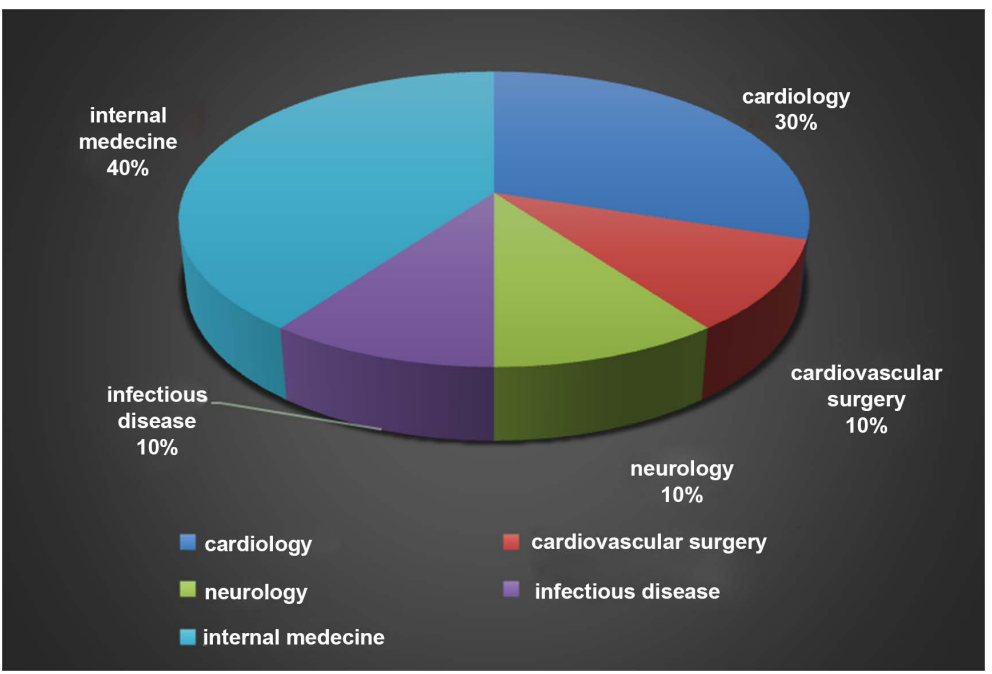

Figure 2. Initial hospitalization service.

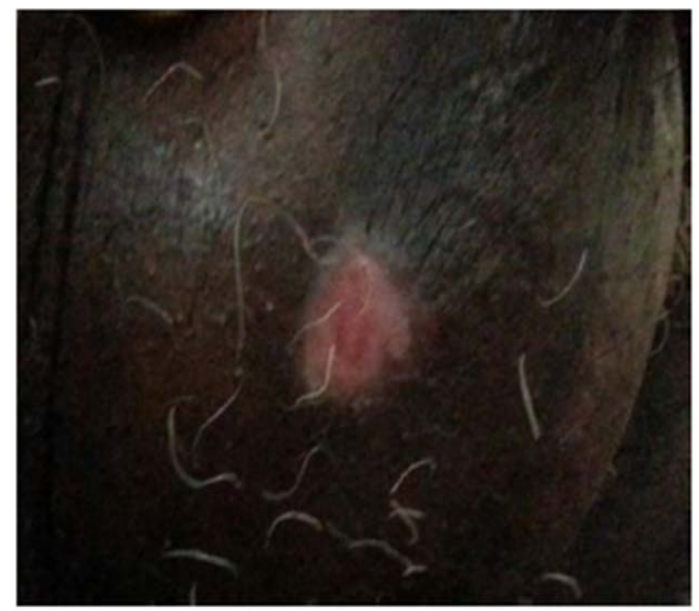

Figure 3. Genital Aphthosis.

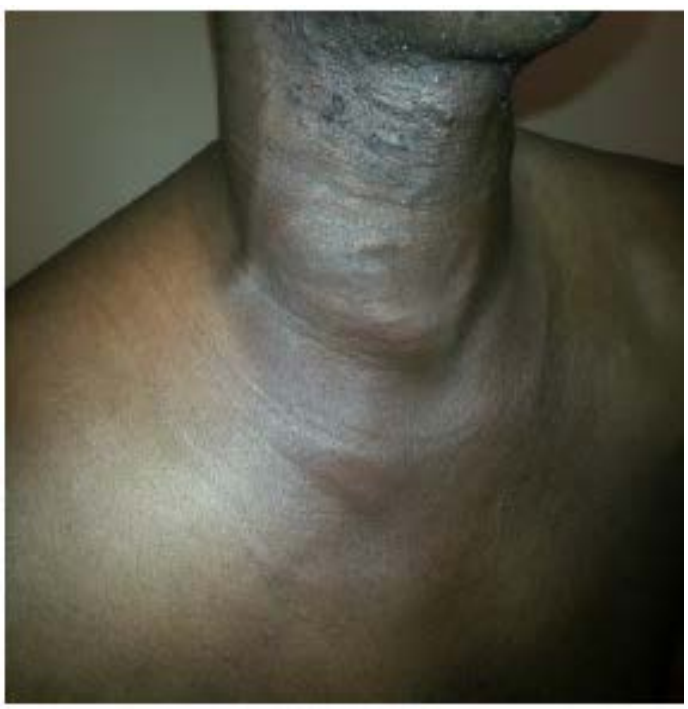

Figure 4. Upper cave syndrome. 


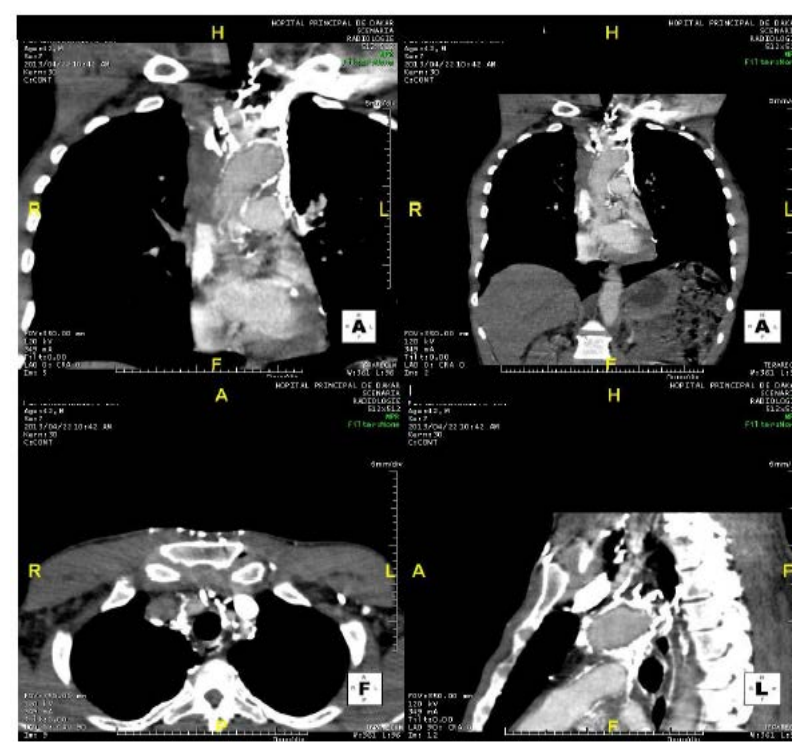

Figure 5. Superior cava thrombosis in TDM.

Table 1. Thrombosis localization.

\begin{tabular}{ccc}
\hline Localization & Case number & Percentage \\
\hline Superior vena cava & 3 & $30 \%$ \\
inferior vena cava & 2 & $20 \%$ \\
Vena of the lower limbs & 2 & $20 \%$ \\
Cerebral vein & 2 & $20 \%$ \\
Axillary vein & 1 & $10 \%$ \\
\hline
\end{tabular}

In Senegal, the largest retrospective series carried out in the Department of Dermatology of the HALD revealed 50 cases in 13 years [6]. This confirmed the ubiquitous nature although it is a rare or under diagnosed disease in Africa.

Most studies agree on the significant predominance of male patients in patients with $\mathrm{BD}$ with vascular involvement compared to those without vascular involvement [7] [8]. This male predominance is also found in our study. Moreover, male hormones aggravate the severity of the disease, and the development of vascular manifestations [9].

In our study, the mean age was 34 years with extremes of 22 and 69 years. The literature review of Behçet's disease indicates that the average age of onset of symptoms is between 26 and 34 years. In terms of the broadest cohorts, we note an average age of 25.6 years in Turkey (2147 patients) [10], 28.8 years in Korea (1155 patients) [11] and 27.5 years in Tunisia (702 patients) [12]. The extreme ages of the occurrence of the disease range from the first months of life to the age of 54 years around the Mediterranean basin, in Europe and in the Arab countries [12]. They could occur up to 72 years of age according to the studies carried out in the Asian countries, having in mind that the occurrence after 60 years of age is exceedingly rare. The rarity of the late occurence of the disease 
makes it difficult to analyze the particularities of such an establishment.

Late cases have been published and these observations have the particularity of associating the involvement of several apparatuses in particular osteoarticular and neurological [11].

The mean time between the onset of the first signs of the disease and the diagnosis of behcet's disease was 30 months. Compared to the largest series of Dakar done in Dermatology (18 months), this delay is long [6]. The delay in diagnosis in our study is probably related to the benign nature of the dermatological manifestations evolving by relapses and remissions and constituting the first symptoms of the disease. Vascular involvement usually occurs a few years after mucocutaneous signs.

The pathogenesis of behcet's disease associates a cellular hyperactivity causing the neutrophils (PNN), T cells, and endothelial cells to interact with the expression of the HSP (heat shock protein).To explain the venous thrombosis during the behcet's disease, 2 mechanisms are offered: vasculitis which can affect the large venous trunks and hypercoagulability blood. The trend thrombogenicity of behcet's disease is due to an inhibition of the fibrinolytic potency of serum and to an increase in platelet aggregability [12] [13]. This is explained by an increase in the von Willebrand factor and a decrease in prostacyclin (PGI2), in relation to a dysfunction of vascular endothelial cells.

Their emboligenic character is certain ( $10 \%$ to $15 \%$ of cases of thrombosis) but less than idiopathic thrombophlebitis [14], due to the inflammatory parietal phenomena.

Pulmonary embolism is rarely observed during behcet's disease and this is explained by the fact that venous thromboses during this disease are not very emboligene because the thrombus adheres strongly to the venous wall [15].

Vascular involvement is seen in 10 to $40 \%$ of BD cases [1]. It is dominated by venous involvement, which accounts for $80 \%$ - 90\% [16].

The diffusion of venous thrombosis to all venous territories is clearly evident in our results confirming the ubiquitous nature of the venous involvement and the venous tropism of the disease [17].

In the order of frequency, venous thrombosis mainly occur in the lower limbs, the superior vena cava, the inferior vena cava and finally in the upper limbs [7] [8] [18]-[23].

In our study, the chest vascular localization, more frequent was found in $3 \mathrm{pa}-$ tients (Figure 3 and Figure 4). The thrombosis of the superior vena cava is therefore possible in Behçet's disease and would represent $2.5 \%$ of cases [6]. However, it is rarely the telling element [22].

Superior vascular thrombosis may be primary or secondary to an extension of axillary or subclavian phlebothrombosis. It usually occurs a few years after the cutaneous mucosal signs of the disease. Rarely, it is inaugural preceding the other manifestations. Clinically, it may be latent, well-tolerated, low-noise, or noisily manifested by chest pain, headache, bilateral papillary edema, fever. It is 
possible to have, associated with the picture, an effusion of the serous ones such in our patient who presented a pericardial effusion. Its nature is sometimes chyleous [5].

Imaging plays a fundamental role in the diagnosis of thrombosis. This is based on the location of the ultrasound, computed tomography and resonance imaging [5].

Given the absence of controlled studies, there is no consensus for the treatment of venous thrombosis during BD [24].

Most authors recommend the use of anticoagulants at curative doses while others avoid their use alone and associate them with corticosteroids because of their ineffectiveness for some, and the risk of bleeding due to an inflammation of the vascular wall [14]. For others, corticosteroids can be used during venous attacks [7]. In our series corticoids were used in all patients.

\section{Conclusion}

Behçet's disease is a disease of the young adult, but it must be evoked even in old age, for an effective mode of treatment in order to avoid the complications of the disease. These complications, which may mask the disease, may lead to a misdiagnosis. Although it is rare in our regions, it should be sought in the etiological assessment of venous thrombosis regardless of the location.

\section{References}

[1] Houman, MH. and Bel Feki, N. (2017) Physiopathology of Behçet's Disease. La Revue de Médecine Interne, 35, 90-96. http://doi.org/10.1016/j.revmed.2013.10.012

[2] Simon, F. and Chouc, P.Y. et al. (1992) Behçet's Disease. Black African Medicine of Black Africa, 39, 658-664.

[3] International Team for the Revision of the International Criteria for Behcet's Disease (2006) Evaluation of the International Criteria for Behcet's Disease (ICBD). Clinical and Experimental Rheumatology, 24 (Supplement 42), S13.

[4] International Study Group for Behcet's Disease (1990) Criteria for Diagnosis of Behçet's Disease. Lancet, 335, 1078-1080.

[5] Zidi, A., Mrad, K.B.M., Hantous, S., et al. (2006) Vascular Behçet with Thoracic Localization. Journal de Radiologie, 87, 285-289.

https://doi.org/10.1016/S0221-0363(06)74002-1

[6] Ndiaye, M. and Sow, A.S. (2015) A Valiollah Behçet's Disease in Black Skin: A Retrospective Study of 50 Cases in Dakar. Journal of Dermatological Case Reports, 9 , 98-102. https://doi.org/10.3315/jdcr.2015.1213

[7] Tohmé, A., Aoun, N., El-Rassi, B. and Ghayad, E. (2003) Vascular Manifestations of Behçet's Disease: 18 Cases among 140 Patients. Revue du Rhumatisme, 70, 766-772. https://doi.org/10.1016/S1169-8330(03)00160-1

[8] Sagdic, K., Ozer, Zg. and Saba, D. (1996) Venous Lesions in Behçet's Disease. European Journal of Vascular and Endovascular Surgery, 11, 437-440. https://doi.org/10.1016/S1078-5884(96)80178-X

[9] Erkan, F., Gül, A. and Tasali, E. (2001) E Rare Diseases. Pulmonary Manifestations of Behçet's Disease. Thorax, 56, 572-578. https://doi.org/10.1136/thorax.56.7.572 
[10] Gurler, A., Boyvat, A. and Tursen, U. (1997) Clinical Manifestations of Behcet's Disease: An Analysis of 2147 Patients. Yonsei Medical Journal, 38, 423-427. https://doi.org/10.3349/ymj.1997.38.6.423

[11] Bang, D. (1997) Treatment of Behçet's Disease. Yonsei Medical Journal, 38, 401-410. https://doi.org/10.3349/ymj.1997.38.6.401

[12] Hamza, M. (2000) Behçet's Disease In: Kahn, M.F., Peltier, A.P., Meyer, O., Piette, J.C., Eds., Systemic Diseases and Syndromes, 4th Ed., Flammarion Medicine, Paris, 883-924.

[13] Özoran, K., Düzgün, N., Gürler, A., Tutkak, H. and Tokgöz, G. (1995) Plasma von Willebrand Factor, Tissue Plasminogen Activator, Plasminogen Activator Inhibitor, and Antithrombin III Levels in Behçet's Disease. Scandinavian Journal of Rheumatology, 24, 376-382. https://doi.org/10.3109/03009749509095184

[14] Otmani, F., Brouri, M. and Bedrane, Z. (1991) Behçet's Disease: A Rare Cause of Pulmonary Embolism. Presse Medicale, 20, 959.

[15] Sakane, T., Takeno, M., Suzuki, N. and Inaba, G. (1999) Current Concepts, Behcet's Disease. The New England Journal of Medicine, 341, 1284-1291.

https://doi.org/10.1056/NEJM199910213411707

[16] Ziadé, N. and Awada, H. (2006) Late Forms of Behcet's Disease. Review of Rheumatism, 73, 957-959.

[17] Ko, G.Y., Byun, J.Y., Choi, B.G. and Cho, S.H. (2007) The Vascular Manifestations of Behçet's Disease: Angiographic and CT Findings. The British Journal of Radiology, 3, 1270-1274.

[18] Kabbaj, N., Ben Jelloun, G. and Gueddari, F.Z. (1993) Vascular Lesions of Behçet's Disease-About 40 Cases. Journal of Radiology, 14, 107S.

[19] Wechsler, B., Piette, J.C. and Conard, J. (1987) Deep Vein Thrombosis in Behçet's Disease. 106 Sites on a Series of 177 Patients. Pre-Medical, 16, 661-664.

[20] Zouboulis, C.C., Kotter, I., Djawari, D., et al. (2001) Adamantiades-Behçet's Disease: Epidemiology in Germany and in Europe. In: Lee, S., Bang, D., Lee, E.-S. and Sohn, S., Eds., Behçet's Disease, A Guide to Its Clinical Understanding, Textbook and Atlas, Springer, Berlin, Heidelberg, 157-169.

[21] Kuzu, M.A., Ozaslan, C. and Koksoy, C. (1994) Vascular Involvement in Behçet's Disease: 8-Years Audit. World Journal of Surgery, 18, 948-953. https://doi.org/10.1007/BF00299119

[22] Mahfoudhi, M., Hariz, A., Turki, S., et al. (2012) Cava Thrombosis Complicating Behçet's Disease. La Revue de Médecine Interne, 33, S105-S106.

[23] Evereklioglu, C. (2007) Managing the Symptoms of Behçet's Disease. Expert Opinion on Pharmacotherapy, 5, 317-328. https://doi.org/10.1517/14656566.5.2.317

[24] Houman, M.H., Smiti-Khanfir, M. and Hamzaoui, K. (2008) Current Treatments and Therapeutic Perspectives in Behçet’s Disease. La Presse Médicale, 37, 25-35. https://doi.org/10.1016/j.lpm.2007.03.037 